\title{
The use of happiness research for public policy
}

\author{
Bruno S. Frey • Alois Stutzer
}

Received: 17 November 2011 / Accepted: 21 November 2011 / Published online: 17 December 2011 (C) Springer-Verlag 2011

\begin{abstract}
Research on happiness tends to follow a "benevolent dictator" approach where politicians pursue people's happiness. This paper takes an antithetic approach based on the insights of public choice theory. First, we inquire how the results of happiness research may be used to improve the choice of institutions. Second, we show that the policy approach matters for the choice of research questions and the kind of knowledge happiness research aims to provide. Third, we emphasize that there is no shortcut to an optimal policy maximizing some happiness indicator or social welfare function since governments have an incentive to manipulate this indicator.
\end{abstract}

Research on happiness ${ }^{1}$ has spurred a lively debate on new directions in public policy. Many governments, international organizations and think tanks commission reports on alternative measures of social progress and their policy consequences. ${ }^{2}$ The scientific

\footnotetext{
${ }^{1}$ The scientific term is subjective well-being. We do not in general distinguish between these concepts but simply use the more popular term "happiness". Distinctions between the various concepts are only made when it comes to particular measurements of subjective well-being and when empirical studies are referred to. Following the literature, the simpler and more popular term happiness is used where suitable.
}

${ }^{2}$ A prominent example is the so-called Sarkozy Report by Stiglitz et al. (2009).

Bruno S. Frey and Alois Stutzer are also associated with CREMA-Center for Research in Economics, Management and the Arts.

\section{B. S. Frey}

University of Warwick, Coventry, UK

B. S. Frey $(\varangle)$

Department of Economics, University of Zurich, Wilfriedstrasse 6, 8032 Zurich, Switzerland e-mail: bruno.frey@econ.uzh.ch

\section{A. Stutzer}

Faculty of Business and Economics, University of Basel,

Peter Merian-Weg 6, 4002 Basel, Switzerland

e-mail: alois.stutzer@unibas.ch 
input, i.e. the theoretical work and the empirical results of the economics, and the closely related psychology, of happiness have been discussed in a number of surveys ${ }^{3}$ and monographs ${ }^{4}$ so that there is no need to review them here. With regard to the policy consequences derived from these discussions, research in this field tends explicitly or implicitly to follow a "benevolent dictator" approach where the government, individual politicians and public officials are assumed to be able and willing to pursue people's happiness or to maximize a social welfare function where individuals' welfare is proxied by individuals' reported subjective well-being.

This article takes a different approach by using the insights of public choice theory to develop the foundations of happiness policy. In particular, politicians are assumed to behave as other members of society and to be self-interested. They have no direct incentive to pursue the happiness of the population. However, they are subject to several constraints on their behaviour, in a democracy the need to gain re-election being particularly important (see, e.g., Mueller 2003). This view of public choice theory neither negates the possibility of happiness policy from a positive perspective nor negates it from a normative perspective. It rather requires an alternative to the social planner approach.

In order to analyze the possibilities and limits of happiness policy, this article therefore uses the public choice perspective in the form of the constitutional approach to political economy. We draw on and extend previous study in Frey and Stutzer (2010) where we focused on how hypotheses of public choice theory can be confronted with evidence in a novel way using data on reported subjective well-being. In this article, we broaden and deepen the constitutional perspective on happiness research already taken up in our earlier study.

The goal of the article is threefold. First, we inquire how the results of happiness research may be used to improve the choice of institutions at the constitutional level as well as the outcomes of the current politico-economic process at the post-constitutional level. We argue and illustrate this by resorting to concrete results from happiness research which show that there are impulses on both levels. Second, our discussion should make clear that the policy approach matters for the choice of research questions and thus for the kind of knowledge happiness research aims to provide, as well as for the people seen as addressees. Third, we emphasize that there is no shortcut to an optimal happiness policy that maximizes some aggregate happiness indicator as a social welfare function. An important reason is that governments have an incentive to manipulate the happiness indicator in their favour.

Section 1 sketches a constitutional framework to "happiness policy". In Sect. 2, we discuss how happiness research may matter at the constitutional level, and in Sect. 3 at the level of the current politico-economic process, i.e. at the post-constitutional level. In Sect. 4, the limitations of an optimal happiness policy are discussed. Lastly, Sect. 5 offers conclusions.

\footnotetext{
3 See, e.g., Frey and Stutzer (2002a), Dolan et al. (2008), Stutzer and Frey (2010).

${ }^{4}$ See, e.g., Kahneman et al. (1999), Frey and Stutzer (2002b), Layard (2005), Diener and Biswas-Diener (2008), Frey (2008), Easterlin (2010).
} 


\section{A constitutional framework to "happiness policy"}

We want to argue that the constitutional approach to political economy championed by Buchanan and Tullock (1962), and further developed in Brennan and Buchanan (1986), offers a framework for a most productive discourse on "happiness policy". No review of this approach is provided here. Rather specific aspects are emphasized to structure thoughts on the use of happiness research for public policy. The two levels at which policy decisions are taken according to the constitutional approach, and the conceptual value of this distinction, are first discussed. General implications also applying to happiness research are then expounded.

The constitutional approach is based on contractarian political philosophy. People are supposed to decide on two policy levels. At the initial level, the rules of the game are set through a voluntary agreement to which all citizens give their consent. A consensus is possible because people make these constitutional decisions behind the veil of uncertainty regarding their own future position. There is a veil of uncertainty as to each person's particular interests and to how exactly the constitutional rules will affect each of them in the future. This construction is normatively appealing, because it rests on a consensus for procedures perceived as productive and fair ex ante. Moreover, imposing only unanimity as a condition, it avoids introducing ethical criteria that are external to the individual. People have different ideas about the good life that motivate them to search for ground rules that best allow them to pursue their ideas.

Implication 1 For positive analysis, the constitutional approach encourages a better understanding of the consequences of alternative institutional arrangements. Different rules have different allocational and distributional consequences. A particular emphasis is thus on rules for choosing rules that overcome individual and short-term interest positions.

While the approach is framed in terms of "constitutional" rules, the range of applications is much broader. First, the ground rules are not only set by the written constitution but also cover basic and unwritten laws and institutions, in particular generally accepted norms and traditions structuring human interaction in a society. Second, on a more general note, this constitutional view emphasizing the institutional framework around any issue can be applied to a wide range of (policy) questions from taxation and savings for retirement, to the organization of firms or the insurance and protection of workers. With regard to taxation, e.g., the constitutional view does not look for the optimal progressivity of an income tax but for the general structure of a tax system and the political decision rules that are applied to decision-making on tax issues (e.g., fiscal federalism, fiscal referendums) in expectation of favourable outcomes including a generally accepted degree of progression in the tax regime (see more fully Brennan and Buchanan (1980)).

The second or post-constitutional level of decision-making considers the setting in which people know their position and therefore their particular interests in society. They play the game within the given written and unwritten constitutional rules. In this state, the existing constitutional order constrains all actors in society, i.e., the politicians and public officials as well as the citizens. 
Implication 2 Individuals demand information on the most productive constitutional rules acceptable to all, for example the conditions under which decentralized decisionmaking is expected to support their preferences, behind the veil of uncertainty. In contrast, in the current politico-economic process political actors demand information that helps them to pursue their private interests.

Based on the two implications derived from the constitutional approach, we see the primary role of publicly funded well-being research in understanding how institutions contribute to people's subjective well-being. Respective insights derived from results of happiness research are presented in Sect. 2. Insights from happiness research are demanded in the current politico-economic process, e.g., in the form of expert reports on the value of specific public goods. Moreover, the citizens will use statistics on aggregate well-being indicators to assess their governments only provided that these sources have informational content (see Sects. 3, 4.3).

\section{Happiness research for the constitutional level of policy}

Happiness research may provide valuable insights on what basic rules and institutions can be set to raise the satisfaction of individuals. However, the research questions have to be formulated in such a way that institutions are related to reported subjective well-being in a comparative manner. This provides the public with access to information about the constitutional provisions that might best allow them to pursue their idea of the good life. Several insights of existing happiness research can be brought to bear for the choice of constitutional rules. They help individuals behind the veil of uncertainty to choose constitutional rules devised on the basis of scholarly inquiry to raise their happiness. Of particular interest would be more results referring to rules for choosing rules, i.e., alternative democratic regimes to delegate decision-making power to elected representatives (see, e.g., Persson and Tabellini 2003), the allocation of decision-making power between competing jurisdictions in a federal system (see, e.g., Frey and Eichenberger 1999), or citizens' involvement in direct democracy (see, e.g., Frey and Stutzer 2006a).

For instance, regarding the latter rule, direct democratic participation rights have been found to be positively related with citizens' well-being (Frey and Stutzer 2000). For the case of Switzerland, people in cantons with more extensive rights to propose popular initiatives and to vote on major laws and constitutional amendments report higher satisfaction with life, many other influences on satisfaction being held constant. This is interpreted as being attributable to the fact that the outcomes of this kind of political process are more beneficial to the population, because politicians are more strongly induced to follow voters' wishes than is the case in a more indirect democracy or a non-democracy. In addition, a comparison between Swiss citizens (who have the right to vote) and foreigners living in Switzerland (who do not have that right but share in the outcomes) shows that citizens value the possibility of political participation, irrespective of outcomes, i.e. they derive procedural well-being from their participation rights.

Happiness research also suggests that decentralized political decisions raise life satisfaction (Frey and Stutzer 2002a). Individuals feel better at ease and better informed 
when decisions affecting local issues are decided at a local level rather than by a centralized government unit sometimes far from the issues at stake.

Existing research on happiness has so far only skimmed the surface of its potential for advancing human well-being by improving constitutional choice. In our mind, this avenue of research promises to become a profound and relevant area of analysis.

A similar constitutional rationale can be applied to general rules to be followed at the post-constitutional level. Some insights have already been gained from comparative analysis. Examples include the effect that a mandatory additional year in school has on reported happiness (Oreopoulos 2007), the relationship between working time regulation and reported subjective well-being (Alesina et al. 2005) or differences in well-being in old age depending on whether retirement is mandatory or not (Charles 2004).

Particularly challenging is the application of a comparative institutional analysis of subjective well-being to individual decisions that are identified by happiness research as being welfare-reducing. This is no easy task as the rational choice perspective in traditional economic theory is poorly equipped to offer guidance in studying systematic (rather than random) errors in consumption choice. Standard economics assumes that perfectly informed individuals are able to predict the costs and benefits of pursuing some activity or consuming some good now and in the future. After people have chosen specific options, these options are implemented without problems. The preferred course of action can be pursued and an individual's behaviour maximizes his or her welfare. This implies that behaviour reveals consistent preferences. Systematic errors in consumption choice are ruled out by assumption. This approach makes it difficult to detect and understand suboptimal consumption decisions due to, for example, problems of limited willpower. Research on subjective well-being offers a new empirical approach for gaining a better understanding of the type of behaviour that might be suboptimal according to individual standards (Stutzer 2009).

Importantly, the constitutional approach does not require a judgment on whether certain behaviour is due to full rationality or to some kind of bounded rationality. It does require, though, that people are or become aware of their limitations in rational decision-making either through self-reflexion or some enlightenment (from, e.g., economic happiness research). In this respect, research moves towards "behavioural public choice". 5 This approach asks for a systematic analysis of the basic rules that impact on any kind of behaviour as well as how such behaviour affects the well-being of people. An example is the systematic misprediction of the utility gained from material goods consumed in the future. Individuals tend to overestimate the satisfaction they expect to achieve. In contrast, they tend to underestimate the future utility gained from relational goods, such as spending time with friends and relatives (e.g., Frey and Stutzer 2006b). People equipped with these insights derived from happiness research might decide to overcome their happiness-reducing behaviours by resorting to collective arrangements. They might, for instance, turn to self-binding mechanisms such as government-mandated maximum working hours and weeks of vacation. In this way,

\footnotetext{
5 In the public choice tradition, of course, the constitutional approach rests on the assumption of rational and purely self-interested actors.
} 
happiness research can also contribute to (constitutional) public policy pertaining to people who are only boundedly rational.

\section{Happiness research for the current politico-economic process}

A major contribution of happiness research that is directly relevant to public policy considers new instruments that enable an individual's experience utility and welfare judgments to be captured. Life satisfaction, happiness, or affect have been measured by various methods. These include representative surveys asking people about their satisfaction with life, positive affect and negative affect; the experience sampling method; the day reconstruction method, and also based on it the U-index (i.e., the fraction of time spent experiencing predominantly unpleasant affects); and brain imaging. Each of the respective methods approaches the theoretical notion of individual welfare from a different perspective. Numerous validation studies document the strengths and weaknesses of the different empirical measures (see, e.g., Frey and Stutzer 2002b; Kahneman and Krueger 2006 and Frey 2008 for references). While the validity of such measures depends on their intended purpose, there is wide agreement among well-being scholars that the measurement methods are sufficiently accurate to derive information on experience utility and individual welfare. There are, however, clear methodological limitations to the measurement of individual welfare as discussed in Sect. 3.1.

As a consequence of the improved information that can be gained about an individual's experience utility and welfare judgments, insights derived from happiness research tend to increase political competition in the current politico-economic process. Politicians, public officials and representatives of special interest groups increasingly appeal to the findings of happiness research as they see it as a means for strengthening their position in the competition for votes or in bargaining for government policies. A case in point is information about the value of public goods and public bads. There is also the hope that a complementary indicator of aggregate happiness might guide policy making more towards citizens' preferences than indicators of aggregate national income alone. In the following, we discuss happiness research in these two areas.

\subsection{Valuation of public goods}

The provision of public goods is a central function of government agencies. More and more often, government agencies are required to provide cost-benefit analyses to back their proposals for government programs. However, the benefits derived from public goods are inherently difficult to measure, because they are not exchanged on markets. In response to the demand by public agencies and private actors, a wide variety of different approaches to measuring preferences for public goods have been developed (see, e.g., Freeman 2003). So far, broadly two kinds of valuation method are applied:

- Stated preference methods Individuals are directly asked to value the public good in question. The most prevalent method is contingent valuation. 
- Revealed preference methods The behaviour of individuals and the complementary and substitutive relationships between public and various marketed goods are used to infer the value attributed to public goods from market transactions in private goods. Examples are the hedonic market approach, the travel cost approach and the averting or mitigating behaviour method, to name only the most prominent ones.

Within happiness research, another promising method is emerging. It is called the "Life Satisfaction Approach" (see Frey et al. 2010). With reported subjective wellbeing as a proxy measure for individual welfare, public goods can be directly evaluated in utility terms. The marginal utility of public goods or the disutility of public bads is estimated by correlating the amount of public goods or public bads with individuals' reported subjective well-being, controlling for many other influences on happiness. By measuring the marginal utility of a public good or the marginal disutility of a public bad, as well as the marginal utility of income, the trade-off ratio between income and the public good can be calculated.

This approach avoids some of the major difficulties inherent in both the stated preference and the revealed preference approaches. In particular, the contingent valuation method of stated preference often faces the problem of the hypothetical nature of the questions asked and the unfamiliarity of the task. The respondents tend to be "primed" to the particular issue in question about which they might otherwise not be much concerned. Moreover, one cannot easily exclude the problem that respondents do not consider their budget constraints and substitutes. Symbolic valuation in the form of attitude expression and superficial answers is likely to result (Kahneman and Knetsch 1992). Similarly, the problem of strategic behaviour of respondents can be addressed only to a limited extent. In turn, the revealed preference method relies on an undistorted equilibrium, in particular on the housing market, where prices reflect individual preferences. However, in many countries, the land, housing and rental markets are characterized by various regulatory restrictions that affect market forces and thus prices. While the Life Satisfaction Approach faces the standard identification problems in empirical work, it is not affected by the particular problems just mentioned. It does not rely on the respondents' ability to consider all relevant consequences of a change in the provision of a public good. It suffices if respondents state their own life satisfaction with some degree of precision. Moreover, there is no reason to expect strategic answering behaviour as long as the collection of statistical data on subjective well-being is not linked to a specific policy goal (see Sect. 4.3). Nor does this approach require undistorted equilibrium prices. ${ }^{6}$

The Life Satisfaction Approach has, for example, been used to value air pollution (Luechinger 2009; Welsch 2006), airport noise nuisance (van Praag and Baarsma 2005), terrorism (Frey et al. 2009), droughts (Carroll et al. 2009), and flood hazards (Luechinger and Raschky 2009). Recent studies have reached a high standard of quality, and more and more preconditions for its application are understood and formulated. What so far was an academically driven development of a new method may soon become an empirical tool meeting demand in the political process.

\footnotetext{
${ }^{6}$ Further accounts on the comparison between the Life Satisfaction Approach and the standard non-market valuation techniques are offered in Kahneman and Sugden (2005) and Dolan and Metcalfe (2008).
} 


\subsection{Aggregate happiness indicators as complements to GNP}

Aggregate happiness indicators are increasingly accepted as complements to the long-established measures of national income, ${ }^{7}$ thus following the lead of the social indicators approach and of the capabilities approach (e.g., Sen 1999). The United Kingdom, Canada and Australia as well as some other countries are committed to producing national measures of well-being. Recently, a specific module was added to the European Social Survey generating comparative information on a wide range of aspects of individual well-being (Huppert et al. 2009).

Aggregate happiness indicators have several interesting qualities in comparison to traditional measures of economic activity. First, national accounts focus on items of market production in an economy that constitute the prerequisites for social life and individual well-being. However, there are many non-material aspects that play a major role in advancing individual happiness. Measures of subjective well-being have the scope to capture aspects beyond market relationships. Of particular importance are social relations, but also the experience of autonomy and competence, and the absence of insecurity. Second, measures of subjective well-being involve judgments about outcome aspects of components which are captured in the national accounts via input measures. This concerns, most importantly, government activity which is of major importance in all societies. A substantial portion of the national product is therefore measured in terms of costs of material and of labour. Third, the empirical indicators of happiness are on purpose subjective, emphasizing the personal evaluations by individuals. This subjectivist approach is in line with the basic methodology used in economics. Other alternatives to the national accounts like the capabilities approach and the "Human Development Index", which is used by the United Nations, look at objectively observable functionings (Sen 1999).

In sum, aggregate happiness indicators provide new and complementary information about preference satisfaction. This information may become a relevant macro input in the political discourse. So far, robust effects of unemployment and inflation on the popularity and re-election support of governments are documented (for a review, see Lewis-Beck and Paldam 2000). This research is based on the idea that voters hold governments responsible for the state of the economy and thereby also fuel political competition incentivizing governments to adopt sound economic policies. An aggregate happiness indicator might intensify this competition as politicians then have the incentive to justify their actions in terms of a broader and better indicator of individual welfare. It is also useful in strengthening the yardstick competition between political units and political parties. This might bring the outcome of the current politico-economic process closer to citizens' preferences.

\section{No shortcut to an optimal happiness policy}

It is tempting to apply subjective well-being measures to improve outcomes by directly maximizing an aggregate happiness measure. This approach considers happiness

\footnotetext{
7 A group of fifty well-known scholars promotes the idea of "National Indicators of Subjective Well-Being and Ill-Being" (Diener 2005).
} 
functions as a reasonably good - or at least the best existing-approximation to a social welfare function. The optimal values of the determinants so derived areaccording to this view-the goals that economic policy should achieve. This goal is not new. Bentham (1789) already dreamed of an economic policy that maximizes social welfare. A later prominent proponent of this idea was Edgeworth (1881). In the contemporary theory of quantitative economic policy, Tinbergen (1956) and Theil (1964) are also partisans to this tradition. Up to now, a major shortcoming of this approach has been that social welfare could not be empirically measured. It seems that the (so far empirically empty) social welfare maximum of the quantitative theory of economic policy has at long last been filled with life. Based on this progress in measurement, it appears that a welfare maximizing macro policy or optimal taxation policy (for a discussion see Weisbach 2008) can be pursued. Indeed, if the accumulated evidence on happiness measures is judged sufficient in the sense that it allows for a cardinal measurement and interpersonal comparison of happiness, then the maximization of a social welfare function is possible. In fact, many different social welfare functions are possible depending on distributional value judgments. The fundamental aggregation problem with ordinal preferences (Arrow 1951; Sen 1970) is then overcome. Following the "dream" of Bentham and Edgeworth, a social welfare function that maximizes mean happiness seems the obvious solution. We see this approach as having three fundamental limitations from the point of view of the constitutional perspective outlined above.

\subsection{Limitation: happiness measures as normative preferences}

As pointed out above, there are many different empirical happiness measures. All of them capture slightly different aspects of individual well-being. This also means that they capture different notions of welfare. What would then characterize a good proxy measure for individual welfare? It is particularly important that the following condition is met: The standards underlying people's judgments must be those the individual would like to pursue in realizing his or her ideal of the good life. A further condition holds that people pursue their individual welfare based on some stable evaluation standards. From these considerations, we conclude that the extent to which individual welfare is identified in empirical happiness research depends on whether the evaluation metric fits people's appraisals of their lives. This argument also reveals the normative basis of the happiness approach. The happiness approach not only assumes the pursuit of happiness, but also involves the choice of a concrete evaluation metric: the metric that is used to elicit people's judgments.

Not surprisingly, different people favour different perspectives. Some people favour the reasoned ex ante evaluations as their standards; others give priority to a distant perspective reflecting on one's life ex post facto. In the latter extreme case, a deathbed evaluation is seen as the only valid appraisal. Still other people focus on their experience of life as it is lived as their standard. Some of these perspectives can be related to specific metrics. Take people who interpret happiness or high standards of individual welfare as a cognitive appraisal of the overall quality of life. For them, general evaluations of their satisfaction with life as a whole might be an appropriate metric to capture 
judgments about individual welfare. Another group are people who equate individual welfare with moment-to-moment affect. For these people, measurement approaches such as the experience sampling method or the day reconstruction method (Kahneman et al. 2004) might be particularly suitable for capturing individual welfare.

The public choice approach to happiness policy does not need to take any stance on these important different evaluations of what well-being means for an individual. For a decision at the collective level, it is important that it is the result of an informed discussion among the individuals (taking into account the pros and cons of various empirical welfare measures) and that the judgments are aggregated in line with rules agreed on at the constitutional level. In a representative democracy, for instance, the respective decisions are taken by a government and parliament that are elected regularly by the voters who respond to their experiences of the past and their expectations about the future behaviour of the politicians they select.

\subsection{Limitation: adaptation and aspirations}

A central finding in happiness research is that many effects of life circumstances have only a short-lived effect on reported subjective well-being. Extreme and well-known examples are paraplegics who after a time of hardship in the long run report themselves to be only a little less happy than before, and lottery winners who after a short period of elation report themselves to be not much happier than before (Brickman et al. 1978). A more recent study based on longitudinal data finds that average life satisfaction drops for people who have suffered a moderate disability but almost regains its pre-disability level after 2 years. In the case of a severe disability the satisfaction measure fails regain its former level (Oswald and Powdthavee 2008).

The second, closely related phenomenon is the change in people's aspirations due to changes in their life circumstances. In the context of economics, an important finding is that people adjust to increases in their income (Stutzer 2004; Di Tella et al. 2007). This process has become known as the aspiration treadmill.

Hedonic adaptation and the aspiration treadmill are not problematic as such for the measurement of individual welfare. However, they have great consequences for social welfare maximization depending on how they are treated. Let us consider the case where courts have to decide about compensation for losses suffered in a car accident. For the same physical harm, should they award lower damages to people with a strong capacity to adapt and higher damages to others? Or in the area of government taxation, what costs of taxation should be taken into account? Materialists with high income aspirations suffer a great deal from personal income taxes. Should they be exempted from tax and government services be financed by people who can easily adapt to whatever material living standard they are confronted with?

What matters in our context is that the means for dealing with hedonic adaptation and the aspiration treadmill are not part of the formal happiness maximization. Yet a decision on how to deal with aspiration changes has to be taken, because it greatly affects the policy to be chosen. It might be decided that the extent of adaptation should not play a role in the compensation of accident victims, for example. Alternatively, if it were decided that the speed and degree of adaptation of accident victims is relevant 
(specified by means of a simple happiness maximization calculus), the courts might be instructed to grant quickly adapting victims lower compensation than slowly adapting victims. The downside of such a policy is that victims would have an incentive to claim that they adapt slowly in order to get the higher compensation. They would be induced to "play the system" instead of reveal their true state of life satisfaction. As a consequence, it is difficult, if not impossible, to determine a compensation that is considered "fair" by the persons involved. The constitutional approach to happiness policy recognizes that the compensation principle to be applied in a particular case by the courts cannot be determined in the current politico-economic process, because the individuals have a stake in the outcome and answer strategically (see also Sect. 4.3). Rapidly-adjusting victims would reject the above policy setup, while slowly-adapting victims would likely support it. A solution can be found at the constitutional level behind the veil of uncertainty in which nobody knows whether he or she will be the victim of an accident or whether he or she is a quick or slow adaptor. A collective decision making rule is required to indicate how adaptation and aspiration effects have to be dealt with in public policy. Obviously such decisions have grave consequences for economic policy, which the social welfare maximization approach does not address. $^{8}$

\subsection{Limitation: incentives for manipulation}

The idea of maximizing social welfare in terms of aggregate happiness rests on the implicit assumption that political actors cannot influence the measurement of subjective well-being. This assumption disregards strong incentives. In fact, the use of aggregate happiness indicators as targets within the political process is expected to induce strategic interactions between the government and citizens. In particular, we see two distortions that limit the informational content of aggregate happiness indicators.

First, there are the incentives of the government, public bureaucracy and interest groups to manipulate aggregate happiness indicators in their favour once they are politically relevant. There are many different possibilities for manipulation. The weight attributed to subindices, for example, leaves many degrees of freedom when building aggregate indicators. Another decision involves the pool of people who are taken into account when subjective well-being is measured. Are the mentally ill, the prisoners or the illegal residents included? How are non-responses dealt with? Imagine the case in which a government or an interest group is unable to manipulate a particular indicator to its benefit. In this situation, the actors have an incentive to create new indicators. Already today, there are a large number of indicators (and variants of these) available (as has been pointed out in Sect. 3). Moreover, aggregate happiness indicators are quite cheap to assemble. While this allows replicating surveys that seem rigged, it

\footnotetext{
8 Related work by Loewenstein and Ubel (2008) emphasizes the shortcomings of measures of experience utility related to the phenomenon of hedonic adaptation; e.g., due to scale recalibration when assessing subjective health. The authors conclude that methods of deliberative democracy could achieve an approach based on decision utility of people who are informed about research on experience utility. Deliberative democracy could thus be interpreted as their constitutional proposal indicating how to deal with the insights on hedonic adaptation.
} 
also allows parties to easily come up with yet another measure serving their interests but confusing voters.

There is evidence of aggregate economic and social indicators having been strategically chosen in many policy areas. While the fundamental concept of the national accounts is fairly standardized, specific GNP figures were "revised" on several occasions when they became important for the survival of a government. For instance, the extent to which the shadow economy is integrated into the official GDP can be varied. Similar adjustments occur if other economic indicators are declared to be goals of government activity. During the recent economic crises, the level of public debt has become a key indicator of government performance. The same held when EU countries had to qualify as members of the then planned European Monetary Union. In both instances, some governments resorted to "creative accounting" (see, e.g., Dafflon and Rossi 1999). Another performance indicator is the rate of unemployment. During the 1980s when the rate of unemployment became a politically important indicator, governments started to influence it in order to present a better image of the state of the labour market than was true. In the UK, for example, the headline number of unemployed was tied to the number of registered claimants. Numerous changes in unemployment insurance coverage affected the figures systematically. Charges of manipulation emerged and " $\mathrm{t}]$ he supporting evidence for these charges has been that all but one of these changes have been unidirectional-downwards" (Gregg 1994, p. 253). ${ }^{9}$ These examples reveal that governments, even in strongly democratic countries, are prepared to manipulate politically important aggregate indicators in their favour.

Second, there are incentives for manipulation on the side of respondents. When happiness indicators influence the behaviour of political actors and their policy choices, individuals have an incentive to misstate their well-being. Imagine that regional differences in aggregate happiness indicators become relevant for transfers between sub-federal units or for regional policy. In this case, the strategic underreporting of subjective well-being is a means by which residents can attract government support. Incentive-compatible reporting schemes for people's subjective well-being present difficulties, and misreporting is cheap. It has thus to be taken into account that people try to "playing the system".

Manipulative incentives can to some extent be counteracted at the constitutional level of policy. Individuals might agree to establish an institution that is independent of government to collect and aggregate data on individual well-being, following the example of central bank independence. The strategic response behaviour of individuals could be neutralized, at least to some extent, by in-depth interviews and the decoupling of surveys from specific policy issues. The efficacy of rules and measuring procedures established to deter political actors from manipulating politically important aggregate indicators remains to be tested.

\footnotetext{
9 Critical accounts of the handling of conceptual and technical instruments in unemployment statistics are offered in Vournas (1999) and Webster (2002). They document how the UK government in the 1980s first changed the definition of unemployment from registered unemployment to claimant unemployment. It followed that, with every reform restricted the access to benefits, the government automatically reduced the official rate of unemployment.
} 


\section{Conclusions}

This contribution argues that the constitutional approach to political economy helps us to understand how the insights of happiness research can be used in public policy. In addition to this positive analysis, the constitutional approach also provides a normative framework to guide happiness research in the field of public policy. In particular, it acknowledges the central role of basic institutions for public policy designed to raise individuals' well-being.

At the constitutional level behind the veil of uncertainty, the fundamental rules and institutions are set which determine the decisions taken in the current politico-economic process. The legitimacy of political action finally rests on the voluntary agreements on these fundamental rules by the citizens involved. In particular, individuals' sovereignty includes the choice of how to best pursue happiness. This holds both for the private as well as the collective realm. The quality of the constitutional provisions is therefore key to people's happiness. We see it as a burlesque of individual sovereignty, if it is reduced to reporting one's well-being, aggregated in a happiness indicator that is then maximized. The constitutional approach does not need to assume that individuals are perfectly rational. Rather, it is accepted that some people are boundedly rational and have limited willpower, and all sorts of other cognitive and motivational limitations. At the constitutional level, individuals who are aware of their own cognitive and motivational limitations, and those of others, will be able choose the appropriate rules governing yet unknown future decisions in which they might get involved.

In sum, we argue that happiness research itself does not offer an approach to public policy. In our view, the fascinating results of this new research area has led to the adoption of a simplistic understanding of public policy. Citizens as ultimate decisionmakers are disregarded, and governments are seen as benevolent maximizers of social welfare captured in terms of measured subjective well-being. This view neglects that people differ in what judgments they consider to reflect their normative preferences. Moreover, the processes of adaptation and aspiration change require a decision on how to treat them in policy decisions. This decision is not part of the social welfare maximization approach. Finally, the social welfare approach neglects the negative incentives for manipulating empirical welfare measures.

We conclude that the political process should be institutionally structured so that people's common interests revealed behind the veil of uncertainty become the principal controlling force. Fundamental institutions, or rules of the game, have to be established which provide politicians and public bureaucrats with incentives and information to adequately respond to people's interests. This path is expected to lead to the best possible fulfilment of individual preferences. Thereby, happiness (in its various forms) need not necessarily be people's ultimate goal. Some people emphasize faith and a life agreeable to God. Others strive for freedom, self-actualization and high self-esteem.

Research in constitutional economics helps us to identify which institutions serve the goal of preference fulfilment. In this context, happiness research provides insights about how and to what extent institutions have systematic effects on indicators of individual well-being. The focus is thus on rules and institutions rather than on specific policy interventions. The range of possible institutions is wide and not restricted to 
written constitutional rules. It also includes social norms, traditions and even selfbinding mechanisms.

Happiness research also helps to improve policy decisions within given rules of the game. The improved measurement of subjective well-being strengthens political competition by allowing decision makers to better evaluate the benefits provided by public goods and to compare various measures assessing the state of society.

The results gained from happiness research should be taken as inputs into the political process. These inputs have to prove themselves in political competition and in the discourse among citizens, and between citizens and politicians. This vision differs fundamentally from an approach relying on the maximization of a social welfare, or aggregate happiness, function.

Acknowledgements We are grateful to Thorsten Henne and the guest editors Ben McQuillin and Robert Sugden for their constructive comments that were most helpful in clarifying our arguments.

\section{References}

Alesina A, Glaeser E, Sacerdote B (2005) Work and leisure in the United States and Europe: why so different?. NBER macroeconomics annual, vol 20. MIT Press, Cambridge, pp 1-64

Arrow KJ (1951) Social choice and individual values. Wiley, New York

Bentham J (1789) An introduction to the principles of morals and legislation. Clarendon Press, Oxford

Brennan G, Buchanan JM (1980) The power to tax. Analytical foundations of a fiscal constitution. Cambridge University Press, Cambridge

Brennan G, Buchanan JM (1986) The reason of rules: constitutional political economy. Cambridge University Press, Cambridge

Brickman P, Coates D, Bulman RJ (1978) Lottery winners and accident victims: is happiness relative? J Personal Soc Psychol 36(8):917-927

Buchanan JM, Tullock G (1962) The calculus of consent. Logical foundations of constitutional democracy. University of Michigan Press, Ann Arbor

Carroll N, Frijters P, Shields MA (2009) Quantifying the costs of drought: new evidence from life satisfaction data. J Popul Econ 22(2):445-461

Charles KK (2004) Is retirement depressing? Labor force inactivity and psychological well-being in later life. In: Polachek SW (ed) Accounting for worker well-being. Research in Labor Economics 23. Elsevier, Amsterdam pp 269-299

Dafflon B, Rossi S (1999) Public accounting fudges towards emu: a first empirical survey and some public choice considerations. Public Choice 101(1-2):59-84

Di Tella R, Haisken-De New J, MacCulloch R (2007) Happiness adaptation to income and to status in an individual panel. NBER Working Paper No. W13159, Cambridge

Diener E (2005) Guidelines for national indicators of subjective well-being and ill-being. University of Illinois at Urbana Champaign, Mimeo

Diener E, Biswas-Diener R (2008) Happiness: unlocking the mysteries of psychological wealth. Blackwell, Malden

Dolan P, Metcalfe R (2008) Comparing willingness-to-pay and subjective well-being in the context of non-market goods. Centre for economic performance discussion Paper No. 0890, London School of Economics

Dolan P, Peasgood T, White M (2008) Do we really know what makes us happy? A review of the economic literature on the factors associated with subjective well-being. J Econ Psychol 29(1):94-122

Easterlin RA (2010) Happiness, growth, and the life cycle. Oxford University Press, Oxford

Edgeworth FY (1881) Mathematical psychics: an essay on the application of mathematics to the moral sciences. Kegan Paul, London

Freeman AMIII (2003) The measurement of environmental and resource values: theory and methods. Resources for the future, Washington

Frey BS (2008) Happiness: a revolution in economics. MIT Press, Cambridge 
Frey BS, Eichenberger R (1999) The new democratic federalism for Europe: functional, overlapping, and competing jurisdictions. Edward Elgar, Cheltenham

Frey BS, Stutzer A (2000) Happiness, economy and institutions. Econ J 110(466):918-938

Frey BS, Stutzer A (2002a) What can economists learn from happiness research?. J Econ Lit 40(2):402-435

Frey BS, Stutzer A (2002b) Happiness and economics: how the economy and institutions affect well-being. Princeton University Press, Princeton

Frey BS, Stutzer A (2006a) Direct democracy: designing a living constitution. In: Congleton R, Swedenborg B (eds) Democratic constitutional design and public policy, analysis and evidence. MIT Press, Cambridge pp 39-80

Frey BS, Stutzer A (2006b) Mispredicting utility and the political process. In: McCaffery EJ, Slemrod J (eds) Behavioral public finance. Russell Sage Foundation, New York pp 113-140

Frey BS, Stutzer A (2010) Happiness and public choice. Public Choice 144(3-4):557-573

Frey BS, Luechinger S, Stutzer A (2009) The life satisfaction approach to the value of public goods: the case of terrorism. Public Choice 138(3-4):317-345

Frey BS, Luechinger S, Stutzer A (2010) The life satisfaction approach to environmental valuation. Annu Rev Resour Econ 2:139-160

Gregg P (1994) Out for the count: a social scientist's analysis of unemployment statistics in the UK. J R Stat Soc A 157(2):253-270

Huppert FA, Marks N, Clark A, Siegrist J, Stutzer A, Vittersø J, Wahrendorf M (2009) Measuring wellbeing across Europe: description of the ESS well-being module and preliminary findings. Soc Indic Res 91(3):301-315

Kahneman D, Knetsch JL (1992) Valuing public goods: the purchase of moral satisfaction. J Econ Manage 22(1):57-70

Kahneman D, Krueger AB (2006) Developments in the measurement of subjective well-being. J Econ Perspect 20(1):3-24

Kahneman D, Sugden R (2005) Experienced utility as a standard of policy evaluation. Environ Resour Econ 32(1):161-181

Kahneman D, Diener E, Schwarz N (eds) (1999) Well-being: the foundations of hedonic psychology. Russell Sage Foundation, New York

Kahneman D, Krueger AB, Schkade DA, Schwarz N, Stone AA (2004) Toward national well-being accounts. Am Econ Rev 94(2):429-434

Layard R (2005) Happiness: lessons from a new science. Penguin, New York

Lewis-Beck MS, Paldam M (2000) Economic voting: an introduction. Elect Stud 19(2-3):113-121

Loewenstein G, Ubel PA (2008) Hedonic adaptation and the role of decision and experience utility in public policy. J Public Econ 92(8-9):1795-1810

Luechinger S (2009) Valuing air quality using the life satisfaction approach. Econ J 119(536):482-515

Luechinger S, Raschky PA (2009) Valuing flood disasters using the life satisfaction approach. J Public Econ 93(3-4):620-633

Mueller DC (2003) Public Choice III. Cambridge University Press, Cambridge

Oreopoulos P (2007) Do dropouts drop out too soon? Wealth, health, and happiness from compulsory schooling. J Public Econ 91(11-12):2213-2229

Oswald AJ, Powdthavee N (2008) Does happiness adapt? A longitudinal study of disability with implications for economists and judges. J Public Econ 92(5-6):1061-1077

Persson T, Tabellini G (2003) The economic effects of constitutions. MIT Press, Cambridge

Sen AK (1970) Collective choice and social welfare. Holden-Day, San Francisco

Sen AK (1999) Development as freedom. Alfred Knopf, New York

Stiglitz J, Sen AK, Fitoussi J-P (2009) Report by the commission on the measurement of economic performance and social progress. http://www.stiglitz-sen-fitoussi.fr

Stutzer A (2004) The role of income aspirations in individual happiness. J Econ Behav Organ 54(1):89-109

Stutzer A (2009) Happiness when temptation overwhelms willpower. In: Dutt AK, Radcliff B (eds) Happiness, economics, and politics: toward a multi-disciplinary approach. Edward Elgar, Cheltenham pp 97-126

Stutzer A, Frey BS (2010) Recent advances in the economics of individual subjective well-being. Soc Res 77(2):679-714

Theil H (1964) Optimal decision rules for government and industry. North Holland, Amsterdam

Tinbergen J (1956) Economic policy: principles and design. North Holland, Amsterdam 
van Praag BMS, Baarsma BE (2005) Using happiness surveys to value intangibles: the case of airport noise. Econ J 115(500):224-246

Vournas Y (1999) Official statistics and the manipulation of conceptual and technical instruments: implications for research on social security. Radical Statistics 72

Webster D (2002) Unemployment: how official statistics distort analysis and policy, and why. Radical Statistics 79/80

Weisbach DA (2008) What does happiness research tell us about taxation?. J Legal Stud 37(S2):S293-S324

Welsch H (2006) Environment and happiness: valuation of air pollution using life satisfaction data. Ecol Econ 58(4):801-813 